\title{
SuperDARN Hokkaido radar observation of westward flow enhancement in subauroral latitudes
}

\author{
R. Kataoka ${ }^{1}$, K. Hosokawa ${ }^{2}$, N. Nishitani ${ }^{3}$, and Y. Miyoshi ${ }^{3}$ \\ ${ }^{1}$ RIKEN, Saitama, Japan \\ ${ }^{2}$ Department of Information and Communication Engineering, University of Electro-Communications, Tokyo, Japan \\ ${ }^{3}$ Solar-Terrestrial Environment Laboratory, Nagoya University, Nagoya, Japan
}

Received: 11 December 2008 - Revised: 18 March 2009 - Accepted: 31 March 2009 - Published: 7 April 2009

\begin{abstract}
Westward flow enhancement in subauroral latitudes is investigated based on the first one and a half year observation of the SuperDARN Hokkaido radar. A total of 15 events are identified with the criteria of westward flow speed of $>1.0 \mathrm{~km} / \mathrm{s}$ in magnetic latitude from 45 to $65 \mathrm{deg}$ during geomagnetically disturbed period of $K_{p}>3+$ at 20 magnetic local time. It is found that especially during the storm recovery phase, the flow enhancement occurs in broad range of $D_{s t}$ amplitude, and the occurrence latitude depends on the amplitude of $D_{s t}$. It is also found that the disturbed $K_{p}$ condition is not sufficient for the appearance of the subauroral flow enhancement as seen by Hokkaido radar while storm-like $D_{s t}$ condition is necessary, supporting the idea that ring current particles play an essential role to enhance the westward flow in subauroral latitudes via magnetosphere-ionosphere coupling through the field-aligned current.
\end{abstract}

Keywords. Ionosphere (Plasma convection) - Magnetospheric physics (Magnetosphere-ionosphere interactions; Storms and substorms)

\section{Introduction}

The subauroral ionosphere and the electric field therein are one of the most important subjects for space weather research because they are directly coupled to the evolution of ring current particles, i.e. the magnetic storm dynamics. During magnetic storms it is possible that the dynamic variation of the ring current particles produce strong subauroral electric fields via magnetosphere-ionosphere coupling. In fact, complicated convection patterns, such as an elongated dusk cell extended to the equatorward edge of the dawn cell, were observed by DMSP satellites during a superstorm (Ebihara

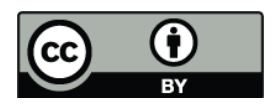

Correspondence to: R. Kataoka (ryuho@riken.jp) et al., 2005), although satellite observations cannot discriminate the temporal/spatial variations. Newly constructed $\mathrm{Su}-$ perDARN Hokkaido radar can address this issue by using the two-dimensional observation of the subauroral electric fields. For example, Ebihara et al. (2008) and Kataoka et al. (2007) compared the observed temporal/spatial variation of subauroral convection pattern with the simulation results from the Comprehensive Ring Current Model (CRCM) (Fok et al., 2001), suggesting that ring current particles play an essential role to enhance the convection flow in subauroral latitudes via the magnetosphere-ionosphere coupling through the field-aligned currents.

It was suggested to use a common term, subauroral polarization streams (SAPS), to characterize the enhanced westward flow appeared equatorward of the auroral oval (Foster and Burke, 2002), since it has been believed that the westward flow is essentially associated with substorms via radial polarization electric fields produced by energetic ion injections into the inner magnetosphere (Koustov et al., 2008). The potential role of ring current particles is, however, still open question. The purpose of this paper is to examine the fundamental question whether the storm condition is necessary or not for the appearance of westward flow enhancement in mid-latitudes based on the first one and a half year observation of the Hokkaido radar.

\section{Data and method of analysis}

The SuperDARN Hokkaido HF radar is capable of measuring the subauroral ionospheric plasma flow especially during magnetic storms when the auroral oval expands to lower latitude than the fields-of-view of the high-latitude SuperDARN radars. The Hokkaido radar was constructed in Rikubetsu town, Hokkaido, Japan at $43.53 \mathrm{~N}$ and $143.61 \mathrm{E}$ in geographic coordinates. The magnetic latitude (MLAT) is 36.46 deg and the L-value is 1.55. The Hokkaido radar has been in

Published by Copernicus Publications on behalf of the European Geosciences Union. 


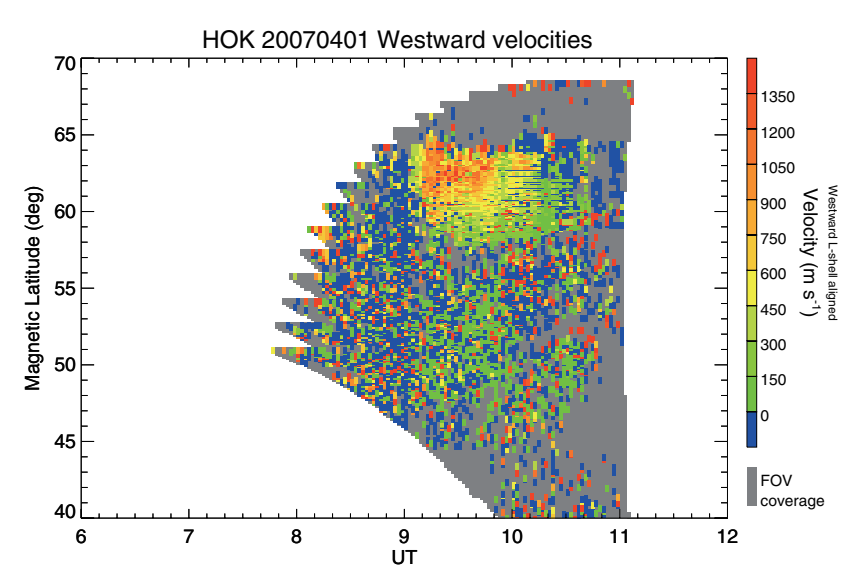

Fig. 1. MLAT-time diagram of westward flow amplitude at 20:00 MLT on 1 April 2007. The westward flow amplitude is estimated assuming the L-shell aligned convection flow.

continuous operation since the beginning of December 2006. The field-of-view (FOV) of the Hokkaido radar extends from 40 to 65 MLAT. A complete scan of the FOV is achieved every $1-2 \mathrm{~min}$.

As shown in Fig. 1, MLAT-time diagram of westward flow amplitude is constructed at 19:30-21:30 magnetic local time (MLT) to find an event, considering the fact that the SAPS amplitude is the largest on average at the 20:00 MLT (Foster and Vo, 2002). The MLAT-time analysis has advantage showing the latitudinal extent and rapid temporal variation of the flow enhancement, both are difficult to investigate by satellites alone. Hokkaido radar FOV scans the 20:00 MLT region from 06:00 to 12:00 UT everyday. In this paper we focus on geomagnetically disturbed time periods of maximum $K_{p}>3+$ during $6 \mathrm{~h}$, when SAPS extends low enough latitudes into the Hokkaido radar FOV on average (Foster and Vo, 2002). In fact, there are few flow enhancement events in subauroral latitudes as observed by Hokkaido radar during less disturbed time periods of the solar minimum.

Westward flow enhancements indeed occur for large $K_{p}$. In fact, Foster and Vo (2002) have reported the strong dependence of SAPS on the $K_{p}$ index. They showed how the latitude of SAPS for a fixed $K_{p}$ value varies with local time and how SAPS moves to lower latitudes when $K_{p}$ increases from 4 to 7. SAPS is essentially a phenomenon during disturbed times and is very weak (or not identifiable) for $K_{p}<4$, and the coherent scatter SuperDARN at mid-latitude may not be able to detect the weak westward flow at small $K_{p}$. The westward flow enhancements tend to occur when $K_{p}$ is large (>4) during magnetic storms.

A typical ionospheric backscatter echo of enhanced westward flow of $>1.0 \mathrm{~km} / \mathrm{s}$ is shown in Fig. 1. The latitudinal extent of enhanced flow is about 6 deg from 59 to $65 \mathrm{deg}$ MLAT, and the duration is about one hour from 09:10 UT. As shown in Fig. 2, NOAA/POES 17 satellite passed over this region at 10:40-10:42 UT, approximately $30 \mathrm{~min}$ after

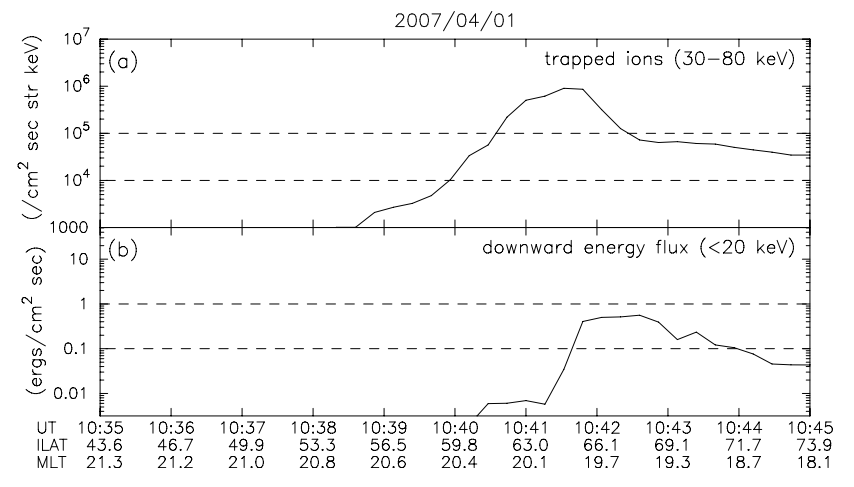

Fig. 2. NOAA-POES 17 observations (Evans and Greer, 2000) crossing over the westward flow enhancement on 1 April 2007: (a) trapped ions of 30-80 keV observed by MEPED and (b) downward electron energy flux of $<20 \mathrm{keV}$ observed by TED. The horizontal dotted lines are used as the threshold values if intersected at clear boundaries.

the event, identifying the low-latitude boundary of auroral electrons of $<20 \mathrm{keV}$ at $65.5 \mathrm{deg}$ and the low-latitude boundary of trapped ions of $30-80 \mathrm{keV}$ at $59.6 \mathrm{deg}$. The horizontal dotted lines in Fig. 2 are used as the threshold values if intersected at clear boundaries. Similar MLAT-time analysis with NOAA/POES data is done for all events to determine the latitudinal boundaries of enhanced flow, auroral electrons, and trapped ions. Further MLAT-time analysis using all available SuperDARN radars would potentially enable us to track the $24 \mathrm{~h}$ evolution of flow enhancements in future.

\section{Results and discussions}

In this paper we are on the simplest interpretation about the appearance of the ionospheric backscatter, assuming that the existence of westward flow enhancement causes very fast growth of the field-aligned irregularities. If we assume that FAIs are generated by gradient-drift instability (GDI), the fastest growth rates are obtained when density gradient and convection are parallel. However, instability can occur everywhere along the boundary of density patches except for an only place where background plasma convection and the electron density gradient are exactly anti-parallel (Keskinen and Ossakow, 1982).

Because of the solar minimum, there are no major storms of $D_{s t}<-150 \mathrm{nT}$ during the first one and a half year time interval from December 2006 to May 2008: The 14-15 December storm is the largest one. Figure 3 shows the $D_{s t}$ and $K_{p}$ profiles during the first 6 month period of the Hokkaido radar observation. As shown in Fig. 3, even in the disturbed condition of $K_{p}>3+$ (diamonds), the westward flow enhancement does not always appear in the Hokkaido radar observation, while the events (arrows) tend to occur during early recovery phase or late main phase. It is also found that there is no significant difference in the $K_{p}$ activities between 


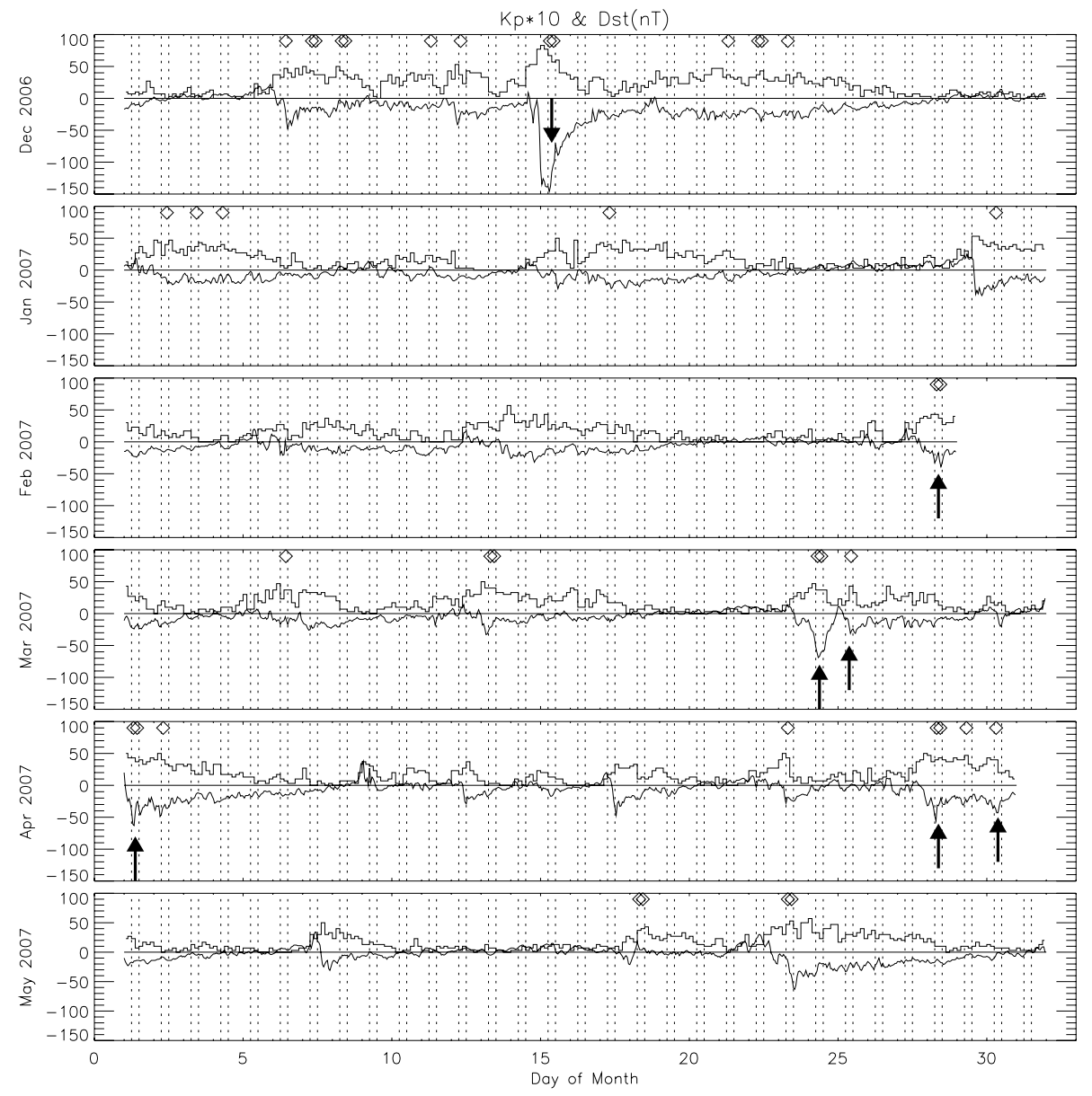

Fig. 3. The $D_{s t}$ and $K_{p} * 10$ indices during the first 6 month period of Hokkaido radar observation. Vertical dotted lines show the time interval from 06:00 to 12:00 UT when the Hokkaido radar observed 20:00 MLT as shown in Fig. 1. Diamonds show the disturbed time period of $K_{p}>3+$, while arrows show the appearance of enhanced westward flow.

the event and no-event. The mean value (standard deviation) of $K_{p}$ index for the event is 3.7 (1.4), while those of the noevent is $3.8(0.8)$. The numbers of events are 15 and 30 for event and no-event, respectively. There is a possibility that the $K_{p}$ independence may lie in the fact that $K_{p}$ is an threehour index and it may smear out any dynamic features of flow enhancement. The minimum AL index of each event is investigated for this purpose (Table 1), but it is actually typical for the corresponding $K_{p}$ index.

Table 1 summarized the event list of westward flow enhancement. The minimum $D_{s t}$ index during the events are shown in the third column, and the association with the storm phase is also shown in the last column. Storm-like condition, monochromatically negative excursion for several hours and then monochromatically positive recovery for a few days, is a necessary condition for all events, regardless of the minimum $D_{s t}$ amplitude ranging from $-116 \mathrm{nT}$ to even positive values. Clear threshold of the minimum $D_{s t}$ value does not exist, and the storm phase dependence is a new result from the current study. It is also worthwhile to note here that, as shown in Fig. 3 (12 December, 13 March, 23 April, etc.), the storm-like $D_{s t}$ variation is not a sufficient condition for the appearance of flow enhancement. Zheng et al. (2008) suggested that the low conductance at subauroral latitude is critical to cause the large amplitude SAPS. Combined research of mid-latitude HF radars and the conductance observations for a number of storms would be needed to clarify the topic in further detail.

Figure 4 shows the latitudinal extent of the westward flow enhancement with the $D_{s t}$ amplitude. The latitudinal extent is not a variation of latitude locations, but a real extent of the westward flow, which is only obtained from the radar observation. It is found that the latitudinal extent does not show clear dependence on any of indices as listed in Table 1; $\mathrm{AL}, \mathrm{PCN}, K_{p}$, and $D_{s t}$. Since the event sample in this study is limited to relatively small storms during solar minimum, the problem should be addressed again including the events in the next solar maximum. The equatorward boundaries of 
Table 1. List of westward flow enhancement as seen by Hokkaido radar.

\begin{tabular}{cccccccc}
\hline Event\# & Date & UT (hour) & $D_{s t}(\mathrm{nT})$ & Storm Phase & $K_{p}$ & $\min$ AL (nT) & $\max$ PCN \\
\hline 1 & 15 Dec 2006 & 9 & -116 & early recovery & $6-$ & -1953 & 7.2 \\
2 & 28 Feb 2007 & 10 & -17 & late main & $4-$ & -614 & 2.8 \\
3 & 24 Mar 2007 & 9 & -69 & early recovery & $4-$ & -1013 & 3.8 \\
4 & 25 Mar 2007 & 9,10 & $-21,-32$ & late main & $4+$ & -927 & 2.8 \\
5 & 1 Apr 2007 & 9 & -42 & early recovery & $4-$ & -427 & 1.7 \\
6 & 28 Apr 2007 & 10 & -32 & early recovery & $4+$ & -679 & 3.4 \\
7 & 30 Apr 2007 & 9 & -43 & early recovery & 2 & -378 & 2.2 \\
8 & 20 Jul 2007 & 8,9 & $5,-13$ & main & 3,4 & -660 & 3.4 \\
9 & 7 Aug 2007 & 9,10 & $-25,-21$ & early recovery & $2+$ & -460 & 2.0 \\
10 & 28 Aug 2007 & 9 & -14 & late main & $4-$ & -828 & 2.9 \\
11 & 28 Sep 2007 & 8 & -21 & late main & $5-$ & -643 & 2.4 \\
12 & 9 Mar 2008 & 8 & -60 & early recovery & 5 & -384 & 2.2 \\
13 & 26 Mar 2008 & 8 & 11 & main & $4-$ & -588 & 3.4 \\
14 & 6 Apr 2008 & 9,10 & $-21,-18$ & recovery & 3 & -688 & 1.7 \\
15 & 23 Apr 2008 & 8,9 & $-19,-22$ & main & $5+, 3+$ & -690 & 4.4 \\
\hline
\end{tabular}

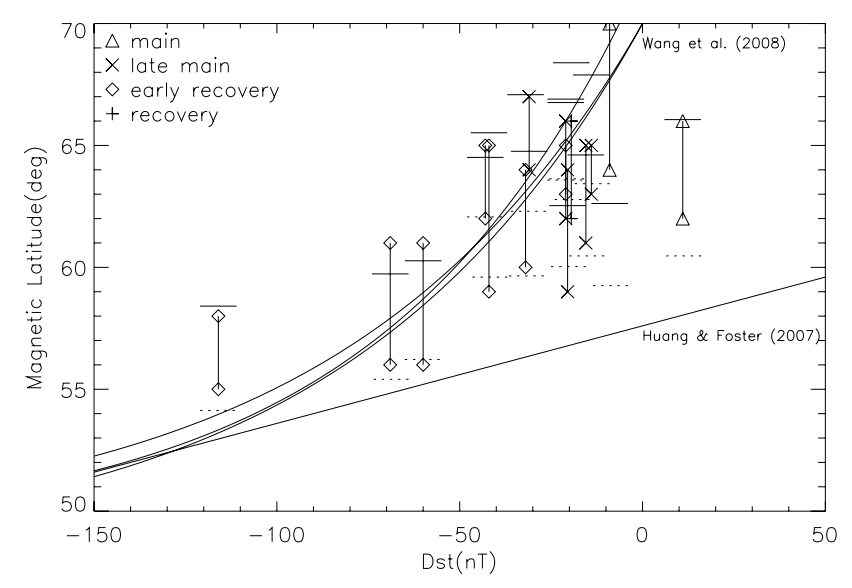

Fig. 4. Latitudinal extent of westward flow enhancement. Empirical SAPS locations as estimated by Huang and Foster (2002) and Wang et al. (2008) are also shown as a function of $D_{s t}$. Horizontal solid and dotted lines show the low-latitude boundaries of auroral electron precipitation and trapped ring current protons.

auroral electron precipitation and trapped protons are estimated by the closest NOAA/POES satellite passage. It is found that all of the events, except for 20 July event (the second event from right-hand side), occurred in subauroral region, and are associated with ring current particles. The dependence of the latitude on $D_{s t}$ is seen in Fig. 3. Especially during the storm recovery phase, the flow enhancement occurs in broad range of $D_{s t}$ amplitude, and the occurrence latitude depends on the amplitude of $D_{s t}$. The $D_{s t}$ dependence, however, is not so clear during the main phase, and such a storm phase dependence is a new finding of this paper. The systematic difference between our events and the prediction curve of Huang and Foster (2007) is not unreasonable be- cause their results are based on only two severe storm events with the minimum $D_{s t}<-200 \mathrm{nT}$, while our events are dealing with only smaller storms.

Recently, Wang et al. (2008) demonstrated a comprehensive statistical analysis using DMSP satellites. Their prediction curves are also shown in Fig. 4 for comparison, which shows more consistent exponential dependence on $D_{s t}$. Also, the PCN index is shown in Table 1 for comparison with their results since they showed a good correlation between polar cap potential and the maximum speed of SAPS. As shown in Table 1, the PCN index is not always high in our events, and seems not to be the necessary condition for the appearance of flow enhancement as seen by the Hokkaido radar.

All of the results shown above are consistent with the generation mechanism of subauroral flow enhancement as described in Kataoka et al. (2007), supporting the idea that the coupling between subauroral ionosphere and inner magnetosphere filled with ring current particles are important to produce the strong subauroral electric field. We are waiting for a number of large storms in solar cycle 24 to test the generation mechanism of subauroral convection flow in further detail, using the mid-latitude radar observations combined with self-consistent ring current simulations as partially done by Ebihara et al. (2008), Zheng et al. (2008), and Koustov et al. (2008).

\section{Summary}

We investigated the westward flow enhancement in midlatitudes based on the first one and a half year observation of Hokkaido radar from December 2006 to May 2008. Especially during the storm recovery phase, the flow enhancement occurs in broad range of the $D_{s t}$ amplitude, and the 
occurrence latitude depends on the amplitude of $D_{s t}$. We did not find significant $K_{p}$ difference between the event and noevent, while storm condition is necessary for the appearance of the westward flow enhancement. Ring current evolution may play an essential role for the westward flow enhancement.

Acknowledgements. RK thanks T. Hori for fruitful discussions. The work by RK was supported by a research fellowship of Special Postdoctoral Research Program at RIKEN. $D_{s t}, K_{p}$, and AL indices were provided by Kyoto University. The PCN index was provided from Danish Meteorological Institute. NOAA/POES satellite data were provided by NOAA. This work was supported by Grant-in-Aid Scientific Research for the Ministry of Education, Culture, Sports, Science and Technology of Japan (19340141). The authors thank the referees for their helpful comments.

Topical Editor I. A. Daglis thanks Y. Zheng and another anonymous referee for their help in evaluating this paper.

\section{References}

Ebihara, Y., Fok, M.-C., Sazykin, S., Thomsen, M. F., Hairston, M. R., Evans, D. S., Rich, F. J., and Ejiri, M.: Ring current and the magnetosphere-ionosphere coupling during the superstorm of 20 November 2003, J. Geophys. Res., 110, A09S22, doi:10.1029/2004JA010924, 2005.

Ebihara, Y., Nishitani, N., Kikuchi, T., Ogawa, T., Hosokawa, K., and Fok, M.-C.: Two-dimensional observations of overshielding during a magnetic storm by the Super Dual Auroral Radar Network (SuperDARN) Hokkaido radar, J. Geophys. Res., 113, A01213, doi:10.1029/2007JA012641, 2008.

Evans, D. S. and Greer, M. S.: Polar orbiting environmental satellite space environment monitor: 2. Instrument description and archive data documentation, NOAA Tech. Memo. OAR SEC-93, NOAA, Boulder, Colorado, 2000.
Fok, M.-C., Wolf, R., Spiro, R., and Moore, T.: Comprehensive computational model of Earth's ring current, J. Geophys. Res., 106(A5), 8417-8424, 2001.

Foster, J. C. and Burke, W. J.: SAPS: A new categorization for subauroral electric fields, Eos Trans. AGU, 83(36), 393, 2002.

Foster, J. C. and Vo, H. B.: Average characteristics and activity dependence of the subauroral polarization stream, J. Geophys. Res., 107(A12), 1475, doi:10.1029/2002JA009409, 2002.

Huang, C.-S. and Foster, J. C.: Correlation of the subauroral polarization streams (SAPS) with the $D_{s t}$ index during severe magnetic storms, J. Geophys. Res., 112, A11302, doi:10.1029/2007JA012584, 2007.

Kataoka, R., Nishitani, N., Ebihara, Y., Hosokawa, K., Ogawa, T., Kikuchi, T., and Miyoshi, Y.: Dynamic variations of a convection flow reversal in the subauroral postmidnight sector as seen by the SuperDARN Hokkaido HF radar, Geophys. Res. Lett., 34, L21105, doi:10.1029/2007GL031552, 2007.

Keskinen, M. J. and Ossakow, S. L.: Nonlinear evolution of plasma enhancements in the auroral ionosphere 1 . long wavelength irregularities, J. Geophys. Res., 87, 144-150, 1982.

Koustov, A., Nishitani, N., Ebihara, Y., Kikuchi, T., Hairston, M. R., and Andre, D.: Subauroral polarization streams: observations with the Hokkaido and King Salmon SuperDARN radars and modeling, Ann. Geophys., 26, 3317-3327, 2008, http://www.ann-geophys.net/26/3317/2008/.

Wang, H., Ridley, A. J., Luhr, H., Liemohn, M. W., and Ma, S. Y.: Statistical study of the subauroral polarization stream: Its dependence on the cross-polar cap potential and subauroral conductance, J. Geophys. Res., 113, A12311, doi:10.1029/2008JA013529, 2008.

Zheng, Y., Brandt, P. C., Lui, A. T. Y., and Fok, M.-C.: On ionospheric trough conductance and subauroral polarization streams: Simulation results, J. Geophys. Res., 113, A04209, doi:10.1029/2007JA012532, 2008. 